\title{
Repositioning the Odl Project in Zimbabwe: The Case of Matabeleland South Zimbabwe Open University Regional Centre
}

\author{
Dr. O. $\mathrm{Mafa}^{1}$ and Mr. D. Ndudzo ${ }^{2}$ \\ ${ }^{I}$ Regional Programme Coordinator, Zimbabwe Open University Bulawayo Region, Zimbwabwe \\ ${ }^{2}$ Registrar, Zimbabwe Open University, Zimbabwe
}

\begin{abstract}
The study focussed on repositioning the Open and Distance Learning (ODL) project in Zimbabwe, using Matabeleland South Zimbabwe Open University (ZOU) Regional Centre as a case study. Data were generated from purposively sampled Regional Centre staff. Data generation was guided by - the perception of Regional Centre staff towards key success factors that influence the competitiveness ODL regional centre; challenges that were contributing towards low student numbers in the regional centre; strategies that the regional centre was using to ameliorate the challenges; and alternative strategies that could be employed to address the problem of low student numbers. Major findings were that: the participants had a positive disposition towards the key success factors; Matabeleland South ZOU Regional Centre is not readily accessible from some of the districts in the province; the regional centre's failure t contextualise some of the key success indicators could be contributing to low student numbers; deploying to different geographical locations alone may not be enough to raise student numbers; and the regional centre seemed to be deficient on core competences needed to contextualise key success factors. Recommendations included - assisting the regional centre to contextualise key success factors; seriously considering some of the alternative strategies that were suggested by the participants; encouraging the regional centre to fully utilise facilities, structures and stakeholders at its disposal in its marketing endeavours; and replicating the study at a macro level so as to enhance the generalizability of the findings.
\end{abstract}

Key words: Zimbabwe Open University, Open and Distance Learning, Key Success Factors, Core Competences; Matabeleland South ZOU Regional Centre

\section{Background to the Problem}

In recent years, registration statistics at The Zimbabwe Open University (ZOU) has plummeted from 20484 in 2005 to as low as 14281 in 2013. This is despite the fact that the ZOU affords students opportunities to learn and earn and that through decentralisation, students can access university education in their own regions without travelling to Harare. In an attempt to reposition the open and distance learning project in Zimbabwe, we decided to establish the perceptions of the ZOU staff towards factors that influence the competitiveness of an ODL regional centre, explore factors contributing to low enrolment figures and strategies that can be adopted by ZOU regional centres to address the problem of low enrolment. We delimited our investigation to Matabeleland South ZOU Regional Centre since statistics indicate that it was one of regions which had consistently experienced low enrolment figures (refer to table 1.1).

Table 1: ZOU's registration statistics for the past five years.

\begin{tabular}{|l|l|l|l|l|l|}
\hline REGION & $\mathbf{2 0 0 9}$ & $\mathbf{2 0 1 0}$ & $\mathbf{2 0 1 1}$ & $\mathbf{2 0 1 2}$ & $\mathbf{2 0 1 3}$ \\
\hline Harare & 4223 & 5078 & 6314 & 5862 & 4843 \\
\hline Bulawayo & 1286 & 1530 & 1753 & 1621 & 1640 \\
\hline Masvingo & 1630 & 1300 & 1366 & 1187 & 999 \\
\hline Manicaland & 1155 & 1460 & 2110 & 2015 & 1788 \\
\hline Mashonaland West & 1162 & 1400 & 1524 & 1456 & 1032 \\
\hline Mashonaland Central & 862 & 1300 & 1167 & 1006 & 952 \\
\hline Mashonaland East & 749 & 1000 & 941 & 787 & 631 \\
\hline Matabeleland North & 484 & 800 & 704 & 645 & 612 \\
\hline Matabeleland South & 384 & 450 & 427 & 415 & 377 \\
\hline Midlands & 1166 & 1300 & 1668 & 1464 & 1281 \\
\hline Virtual Region & & & & $\mathbf{1 6 4 5 8}$ & 126 \\
\hline Total & $\mathbf{1 3 1 0 1}$ & $\mathbf{1 5 6 1 8}$ & $\mathbf{1 7 9 7 4}$ & $\mathbf{1 4 2 8 1}$ \\
\hline
\end{tabular}

Matabeleland South ZOU Regional Centre is situated in Gwanda town - the provincial capital of Matabeleland South Province. The regional centre operates from two places - the government complex which houses the Regional Director, Regional Programme Coordinators, administrator, student advisor, accounts department, regional quality coordinator and data capture clerks. The library and the module stores are accommodated at a 
post office in Jahunda residential area, which is about seven kilometres away from the complex where other units are located.

Matabeleland South is made up of seven districts namely - Gwanda, Matobo, Beitbridge, Insiza, Umzingwane, Bulilima and Mangwe. People from parts of Matobo, Bulilima and Mangwe pass through Bulawayo enroute to Gwanda. Our assumption is that prospective students from these three districts are likely to enrol at ZOU Bulawayo. Similarly, prospective students from Umzingwane and Insiza districts may find it easier to access services in Bulawayo. This effectively reduces ZOU Matabeleland South ZOU's catchment area to two districts - Gwanda and Beitbridge. Faced with this situation the management of Matabeleland South Region ZOU has to address the following questions: (a) Should the Region limit its efforts to Gwanda and Beitbridge Districts? (b) Should the Region endeavour to cover all the seven districts? (c) What are the financial and logistical implications of covering the whole Matabeleland South Province? These questions should be reflected on honestly if ZOU is to successfully reposition the ODL project in the Matabeleland South Province.

\section{Statement of the Problem.}

Given the above background, the problem under consideration in this investigation is how to reposition the ODL Project in Matabeleland South Province by establishing perceptions of regional staff towards factors that influence the competitiveness of an ODL regional centre and exploring limitations militating the growth of an ODL Regional centre.

\section{Purpose of the Study}

The primary aim was to facilitate the growth of the ZOU Matabeleland South Regional Centre by investigating reasons for declining enrolment figures. The secondary aim was to suggest strategies for stimulating the growth of the Region.

\section{Research Objectives}

- $\quad$ To establish the perceptions of Matabeleland South ZOU Regional Centre staff members towards factors that influence the competitiveness of an ODL Regional Centre;

- To investigate the causes of low student enrolment the Matabeleland South ZOU Regional Centre;

- To find out the strategies being used by Matabeleland South ZOU Regional Centre to address the problem of low enrolment; and

- To explore alternative strategies that can be pursued in order to reposition the ODL project in Mat South

\section{Research Questions}

- What are the perceptions of Matabeleland South ZOU Regional Centre staff members towards factors that influence the competitiveness of an ODL Regional Centre?

- What are the causes of low student enrolment at the Matabeleland South ZOU Regional Centre?

- How is the Matabeleland South ZOU Regional Centre addressing the issue of low student enrolment?

- What alternative strategies can be used by the ZOU Matabeleland South Regional Centre to increase student enrolment as the University moves towards repositioning the ODL project?

\section{Limitations of the Study}

The generalizability of the findings to ZOU's other regional centres should be done with caution since data were collected from one regional centre. However, the usefulness of this study is that if findings are deemed to be very useful, the study can be replicated in ZOU's other regional centres. Further triangulating data sources enhanced the trustworthiness of the findings. Triangulation was achieved by collecting data from academic staff, support staff and from security staff.

\section{Delimitations of the Study}

The study was limited to investigating perceptions of participants towards factors that influence the competitiveness of an ODL regional centre; challenges contributing to low student enrolment; strategies being employed by the Region to increase student enrolment. Study participants were drawn from ZOU Matabeleland South Regional Centre staff.

\section{Significance of the Study}

The study illuminated the perceptions of participants towards factors that influence the competitiveness of an ODL regional centre; unmasked challenges contributing to low student enrolment at ZOU Matabeleland South Regional Centre; and recommended alternative strategies that can be put in place for the successful repositioning of the ODL Project. 


\section{Definition of terms}

Core competences: In this study, this refers to capabilities, skills and attitudes that the regional staff members should possess to enable them to contextualise key success factors at the regional centre level.

Key success factors: As used in this study, this refers to essential services, facilities, logistics and infrastructure that are prerequisites for the competitiveness of an ODL regional centre.

Open and Distance Learning: We adopted the definition by The Commonwealth of Learning (2004) where ODL is viewed as an amalgam of two approaches to forms of education that focus on expanding access to learning. It is characterised by its philosophy and its use of technology. Most ODL systems have a philosophy that aims to: remove barriers to education; and allow students to study what they want, when they want, and where they want. ODL systems use technology to mediate learning; for example: modules, audio cassettes, radio, and the web.

\section{Review of Related Literature}

The UNESCO Institute for Information Technologies in Education(IITE) (2000) states that the history of correspondence and distance education demonstrates some of the enduring characteristics of this form of learning: its diversity in terms of level and students, ranging from primary to higher education, from young children to mature adults; the subjects taught, as various as shorthand, mining, and general education; the range of methods used, including correspondence, print, radio and TV, practical work, open examinations; the variety of countries where it has been established (developed, developing, large and small); and the way in which it has responded to social and historical challenges (distributed and displaced populations, imperialism and independence, war and revolution, industrialisation). In the new millennium as we move towards the Information Society, distance education will play an increasingly important role and continue to demonstrate its flexibility and diversity.

\subsection{Factors determining growth of ODL institutions}

Factors affecting the organisation of distance education and the model adopted include aspects of the country involved such as population, land area, political structure, GDP per capita, elite or mass higher education; stakeholder influences, including the relative influence of government, the institutions, the market and private sector; and institutional characteristics: their history, purpose, size, catchment area, use of technology (IITE, 2000). Manal, Kami and Ahmed (2007) state that use of various media, levels of interaction, quality of instructors and use of relevant technology influence the students' decisions to withdraw or complete their studies in a given ODL institution. Howell et al. (2003) opine that ODL is affected by student enrolment trends, faculty trends, academic trends, technology trends, economic trends, distance learning trends as well as trends informing vision.

A number of sources cited by Ali and Ahmed (2011) underscore the importance of instructors in ODL. The general disposition is that instructors must understand the increased diversity of students, and then accordingly determine test formats, measurement practices, and assessment strategies which persuade and motivate students to accept e-learning. There is need to cope with the distance between the tutor and the student by adopting careful teaching strategies based upon well-designed learning materials, a tutoring support system and thorough monitoring of all aspects of the system's operation, including students' performance.

Monetary support, pedagogical competency of online instructors, improvement in online technologies, marketing, rigorous quality management in the accreditation process are some of the factors that will significantly affect the success of ODL programmes (Bonk, 2006). With special reference to ODL in Uganda, Basaza et al. (2010) state that infrastructure development, cost of higher education, relevance of the curriculum, inadequate expertise in ODL and poor attitudes towards ODL are some of the challenges affecting ODL. In our view, some of these challenges could be contributory factors to low student enrolment figures at ZOU.

\subsection{Strategies for addressing declining student numbers}

A number of sources among them The Commonwealth of Learning (2000); Tresman (2002), Bonk (2006), Manal et al. (2007); Angelino, Williams and Natvig (2007), suggest that declining student numbers in ODL institutions can be addressed by the following strategies:

\subsubsection{Managing Open Entry - Where the Learning Journey Begins}

The concept of open entry brings with it potential pitfalls, the most notable being that the University's open door policy must be closely monitored so it does not become a "revolving door policy," where students are admitted only to subsequently withdraw somewhere along their learning journey.

One strategy is that higher education institutions must ensure students are not pitched into a level of study in which they cannot possibly cope. By paying close attention to admissions policies (e.g., entry restrictions to higher level courses, the use of course prerequisites, preferred entry courses at the lowest/lower course level(s), 
providing bridging or preparatory work prior to commencing courses of study, adequate testing and guidance from the outset), institutions can help their students achieve their educational goals in a realistic, step-by-step manner.

1.2.2 Provisions for Specialised Advisory and Guidance Staff - Help Students Make Informed Choices

By providing specialized advisory and guidance staff to assist students in the course selection process, students are more likely to make "informed choices" regarding their course of studies. Clearly, informed choices make for informed students who know what they can expect.

\subsubsection{Provision of Accurate and Relevant Information - When Faced With a Wide Array of Courses,} Students Must Navigate a Complex Set of Possible Choices

By ensuring that pre-course information accurately reflects the courses offered, as well as the distance mode of study practised, students are more likely to succeed in their studies, because their expectations will be more in tune with the realities of the course. The alignment of student expectations with the realities of a given course can thus be achieved by making available a coherent set of information resources (e.g., brochures, course calendars, web sites, face-to-face counselling, information sessions, etc.) that consistently describe both the demands distance education will place on students' lives, as well as a preview of curriculum on offer.

Starting from when students first apply for a course, information must be collected about students' individual intentions related to their expectations. This data collection process will help to frame and address individual educational needs, as well as ascertain what a given student perceives as "success." For some students earning a formal award will be perceived as central to their success, whereas for others, any knowledge gained is perceived a "success."

\subsubsection{Forging and Establishing Relationships - Institutions Must Proactively Focus On Establishing Relationships with New and Returning Students}

Within the framework of gathering, designing and disseminating general and in-depth information about the institution and its courses, a "student induction programme" can serve to welcome both new students and those who return after taking a break from their studies. Such a programme will help to forge lasting relationships with new students and re-establish ties with those returning.

A human face can be put on distance learning by promptly matching students with a tutor who will not only shoulder responsibility for overseeing student progress, but who will also monitor and contact students perceived as being at risk of dropping out. Other useful strategies to enhance retention include establishing peer support networks to motivate students.

\subsubsection{Course Design - Producing and Presenting Courses Well Suited to Students' Needs}

Evidence gathered from various surveys conducted as part of the Open University's Retention Programme (supplemented with data from other areas of the university and external peer reviews) present a compelling case that issues of workload, density of concepts being taught, and the pace and manageability of the various study programmes, are all major factors that may potentially lead to students withdrawing. To combat this problem, curriculum reviews paying particular attention to student workload issues, need to be conducted at regular intervals. Where feedback indicates low student performance is linked with low satisfaction levels, it is suggested that course workload be re-examined to ensure it places realistic demands on students while remaining true to learning outcomes. It is also good practice to produce and apply standardised study templates for use across all academic units. This level of standardization helps to identify study patterns and define varying levels of workload. Within this context, curriculum managers are often helpful in providing additional guidance to students on managing workloads and promoting study skills.

Another good practise is the establishment of annual retention indicators as a central part of an internal curriculum review process. By analysing retention rates alongside other evidence uncovered during the curriculum review process, changes may be discovered that are required to improve curriculum. It is important to set retention benchmarks based on linked (feedback and attainment) performance indicators, specific to different academic units.

Procedures (i.e., rescue strategies) may also be put in place that allows students to officially interrupt their studies should extenuating circumstances dictate. Students should be permitted to carry forward any credits earned up to that point, so long as they choose to recommence their work within a reasonable period of time. Finally, student achievement should be rewarded in a consistent manner that is meaningful to the student.

\subsubsection{Student Support Services - Ownership of Students Support Services Helps Measure Success}

There must be a system of formal "process ownership" within various sectors of the university community. It is important for "process owners" to be able and willing to assist students through critical 
retention milestones such as the application process, course selection, studying for exams, and providing afterexam support. Each "process owner" needs to understand the fundamentals of two-way communication and the role on-going support plays in encouraging persistence and discouraging withdrawal

\subsubsection{The Educational Community - Develop a Sense of Community That is Relevant in a Distance Education Setting}

By developing peer support and mentoring networks, the student experience can be greatly enhanced. Such networks can include student ambassadors, career advisors, and academic and course counsellors. For those students who choose to leave the university for any reason, mechanisms must be established to encourage these "drop-outs" to someday return to their studies. This can be achieved by following-up with telephone calls, formal correspondence and the like.

\subsubsection{Retention Bonuses - Develop "Retention Friendly" Financing and Incentive Schemes to Encourage Student Persistence.}

Good tools to consider are loyalty bonuses, vouchers, discounts that reward successful course completion and graduation incentives for students who are "nearly there."

In our view, any attempts to reposition the ODL project in Zimbabwe should take cognisance of some of the strategies discussed above.

\section{Research Methodology and Design}

The investigation adopted a qualitative case study design. However, the perceptions of participants were measured using a Likert scale. The justification for using such a study design is that the study was meant to get views on the phenomenon under investigation from the perspective of the participants. The design also provided us (researchers) an opportunity get more information that would have been impossible to obtain by using a descriptive survey (Creswell, 2009). Purposive sampling enabled us to identify data rich sources (Kumar, 2005). Data were generated through the use of a questerview - which is a form of an open-ended questionnaire. We favoured the use of such an instrument for two reasons - first, there was anonymity since some participants do not want to be associated with data, especially if data are sensitive; second, the questerview provides participants with ample space to air their views on the issues under investigation.

\section{Findings and Discussions}

\subsection{Biodata of participants}

Table 2: Biodata of participants

\begin{tabular}{|l|l|l|l|}
\hline Occupation & Number & Qualifications & Experience \\
\hline Regional Director & 01 & Masters Degree & $5-7$ years \\
\hline Regional Programme Coordinators & 04 & Masters Degrees & 5 years \\
\hline Administration Officer & 01 & MSc in Counselling & 5 years \\
\hline Student Advisor & 01 & MSc in Counselling & - \\
\hline Works Assistant & 01 & National Diploma & 3 years \\
\hline ICT Technician & 01 & BSc Computers & - \\
\hline Messenger & 01 & 'O' Level & - \\
\hline Accounts Clerk & 01 & HND in Accounting & \\
\hline Stores Clerk & 01 & Certificate in Accounting & $6-7$ years \\
\hline Data Capture Clerks & Diploma; BSc & 3 years \\
\hline Security Guard & 02 & 'O' Level & National Certificate in Secretarial \\
\hline Secretary & 01 & Studies & 7 years \\
\hline Library Assistant & 01 & NDL \&BA Media Studies & \\
\hline
\end{tabular}

The biodata of participants indicate that almost all the categories of ZOU's regional centre staff members were represented. This augured well for the study since it ensured that data sources were triangulated, which is one way of enhancing the trustworthiness of findings in qualitative research. Most of the participants had worked in the regional centre for a period of three years and above. All other things being equal, participants had experienced the phenomenon that was being investigated such that they were likely to provide credible responses.

\subsection{Perceptions of participants towards key success factors that influence the competitiveness of an ODL Regional Centre?}

Perceptions of participants were measured on a Likert scale. However, due to the size of the sample no meaningful statistical calculations could be made, as a result frequencies were tabulated and are thus presented as percentages. 
Table 3: Perceptions of participants on key success factors influence the competitiveness of an ODL Regional Centre

\begin{tabular}{|l|l|}
\hline Key success factors & Percentage \\
\hline Ability to produce high quality learning materials in multi-media form & 76 \\
\hline Ability to deploy in different geographical locations & 94 \\
\hline Robust and relevant ICT for both administrative and teaching purposes & 76 \\
\hline A well-resourced and online library & 59 \\
\hline An effective and efficient learner support system & 94 \\
\hline A credible examination management system & 100 \\
\hline Infrastructure & 76 \\
\hline Resource mobilisation and stakeholder support & 82 \\
\hline An effective quality assurance system & 88 \\
\hline An effective staff attraction/retention regime that attracts top professors & 88 \\
\hline An effective Alumni body whose members act as ambassadors of the University & 82 \\
\hline An effective customer care and loyalty programme & 94 \\
\hline Collaboration for resource pooling and knowledge sharing & 88 \\
\hline Benchmarking against internationally recognised institutions & 82 \\
\hline An aggressive research culture & 82 \\
\hline A sound corporate governance system & 94 \\
\hline An effective and supportive student body & 100 \\
\hline An effective marketing/public relation function & 65 \\
\hline The use of advisory boards when coming up with new faculty programmes & 82 \\
\hline A supportive/conducive legal-politico economic framework/environment & 94 \\
\hline
\end{tabular}

The participants displayed a positive perception towards key success factors that enhance the competitiveness of an ODL regional centre. This augurs well for the university. We suggest that efforts be spent in assisting the regional centre to contextual all these key success factors at regional level. The effect of most of the success factors in Table 2 on the competitiveness of and ODL institution is corroborated by scholars such as Tresman (2002), Bonk (2006), Manal et al. (2007) and Angel, et al. (2007).

However, of some concern is the comparatively low percentage of participants who perceived an effective marketing/public relation function as a key success factor. This could mean that marketing activities were not being taken seriously at the regional centre or that only certain individuals at the regional centre were involved in marketing, instead of making marketing of the university's programmes the responsibility of all the regional centre staff members.

After establishing the perceptions of regional staff members towards key success factors, we explored the extent to which these key success factors were contextualised at the regional centre. Participants were requested to indicate whether or not the key success factors in question were operational at the regional centre. Table 4 presents our findings.

Table 4: Participants' views on the presence and absence of key success factors in their Regional Centre

\begin{tabular}{|l|c|}
\hline Key success factors & $\begin{array}{l}\text { Percentage of participants who affirmed that factors } \\
\text { were contextualised at regional centre. }\end{array}$ \\
\hline Ability to produce high quality learning materials in multi-media form & 29 \\
\hline Ability to deploy in different geographical locations & 47 \\
\hline Robust and relevant ICT for both administrative and teaching purposes & 29 \\
\hline A well-resourced and online library & 00 \\
\hline An effective and efficient learner support system & 59 \\
\hline A credible examination management system & 94 \\
\hline Infrastructure & 47 \\
\hline Resource mobilisation and stakeholder support & 35 \\
\hline An effective quality assurance system & 94 \\
\hline An effective staff attraction/retention regime that attracts top professors & 53 \\
\hline An effective Alumni body whose members act as ambassadors of the & \\
University & 59 \\
\hline An effective customer care and loyalty programme & 53 \\
\hline Collaboration for resource pooling and knowledge sharing & 29 \\
\hline Benchmarking against internationally recognised institutions & 18 \\
\hline An aggressive research culture & 53 \\
\hline A sound corporate governance system & 71 \\
\hline An effective and supportive student body & 82 \\
\hline An effective marketing/publication relation function & 29 \\
\hline The use of advisory boards when coming up with new faculty programmes & 12 \\
\hline A supportive/conducive legal-politico economic framework/environment & 41 \\
\hline
\end{tabular}

Several key success factors appeared not to have been contextualised at the regional centre. Lack of ICT facilities mean that students cannot register online, neither can they consult their tutors, peers and submit 
assignments online. E-learning, one of the hallmarks of ODL cannot be practised. The same can be said on the absence of online library - it means that some students have to travel over 400 kilometres to and from the regional centre to access the library. This could be a deterrent that may result in low enrolment. Haughey et al. (2008) and Bates (2008) in Arinto (2013) argue that many distance education institutions have shifted from a print-based mode of delivery to online delivery characterised by the use of virtual learning environments (VLEs) and various web technologies. It is our view that Matabeleland South ZOU Regional Centre should not lag behind.

Findings suggest that marketing activities are limited. In this cut-throat competition where most of the country's conventional universities are also doubling into ODL through Block Release programmes, the importance of marketing cannot be overemphasised.

The non-existence of an advisory board on issues pertaining to introduction of new causes mean that the regional centre may not be having input into decisions pertaining to introduction of news programmes. This may mean that programmes relevant to stakeholders in Matabeleland South Province are not part of the university programme, prompting potential candidates to enrol in other universities where their programmes of choice are offered.

A question begging for attention is: Why is that a number of key success factors were not contextualised that the regional centre yet in Table 4.1 participants displayed a positive disposition towards these key success factors. A possible answer could be that perhaps most participants felt that it was the responsibility of the University's senior management to ensure that the factors are in place. Second, it could also mean that the participants were of the view that certain factors were only operational at the university's macro level, and not at the regional level. The third possible explanation could be that the regional centre lacked the core competences necessary for contextualising the key success factors at the regional level.

\subsection{Causes of low student enrolment at Matabeleland South ZOU Regional Centre}

Participants highlighted a number of causes. In this section, we present and discuss causes that were frequently mentioned by the participants.

\subsubsection{Very low marketing activities}

All most all the participants mentioned that low student numbers in the regional centre was a result of low marketing activities. Most of the participants' views on marketing were aptly captured by one participant who quipped that:

There is lack of a robust marketing strategy that is consistently funded and grassroots based. This is compounded by lack of a full-time marketing officer dedicated to mouth-by-mouth attention and followups, plus on-going market research across the province . . limited resources - unsuitable vehicle, funds for fuel and subsistence, marketing kit items, etc.

There is no doubt that marketing plays a pivotal role in sensitising potential students about the programmes offered by the university. However, in our view, it appears as if the Regional Centre is not exploiting the facilities, structures and opportunities at its disposal to effectively market its programmes in the seven districts of the province. Examples of such structures and opportunities are the provincial governor's office as it is linked to provincial districts and structures of teacher organisations such as Zimbabwe Teachers' Association (ZIMTA), Progressive Teachers' Union of Zimbabwe (PTUZ), subject teachers' associations, national associations of secondary and primary school heads and district and regional sporting activities.

Lack of effective marketing could also be linked to the Regional Centre's failure to withstand the stiff competition offered by conventional universities, a challenge that was pointed out by some of the participants. This was in relation to the launching of block release programmes by conventional universities. We view competition from other universities as the proverbial burning platform that the Regional Centre should stand up to. It is the Regional Centre's obligation to devise survival strategies, one of which is effective and aggressive marketing.

\subsubsection{Geographical location of the Regional Centre and its inability to deploy to different parts of the Region}

Participants lamented the inaccessibility of the regional centre to students and potential students in some of the province's districts. One participant explained that: 'Some schools, police stations, hospitals and government offices are out in the rural areas and there is need to reach out to the potential students there.' Another participant reiterated: 'Geographical location as some of our clientele opt to go to the Bulawayo Region which is nearer or easily accessible, e.g. Matobo, Umzingwane, Insiza, Bulilima, and Mangwe, leaving us with Gwanda and Beitbridge Districts.' Yet another one pointed out that: 'Lack of effective road network which directly links the regional centre and feeder districts resulting in some potential students enrolling with other centres which are directly linked to them.' In a study by Mafa, Mpofu and Chimhenga (2013), students 
reiterated that the cost of travelling to and from the regional centres was prohibitive and suggested that district centres be opened where students could access the services.

\subsubsection{Fees Structure}

The general consensus was that the fees that were being charged by the university were beyond what most potential students could afford. This argument was premised on the realisation that most potential students were civil servants whose salaries were very low. In addition participants argued that the province in which the regional centre was located was one of poorest provinces which experienced perennially low per capita income. The bottom line was that low disposable income made it difficult for potential students to enrol for university education. As succinctly narrated by one participant:

Conditions on fees registration payment - for example they firstly announce that registration and is $\$ 500$ in cash ... yet other universities allow deposits to be paid. Then later when the dates of registration are overdue and the enrolment is low they announce that even if a student with a deposit of half can register. But the majority would be gone to register to other universities.

\subsubsection{Outstanding student queries}

The participants' sentiments were that this problem affected students who were already in the system and need to be retained. Outstanding queries such as missing results were likely to have a negative effective on affected students. Such students, instead of being good ambassadors for the university by encouraging their friends and relatives to study with the university, may actually discourage them from doing so. However, in our view, most students' queries are a result of mistakes originating from regional centres. Therefore, if regional centres avoid such mistakes, students' queries will not come back to haunt the regional centres.

\subsubsection{Suspension of some programmes by Zimbabwe's Council of Higher Education (ZIMCHE)}

Even though the BSc Counselling Degree programme was later reinstated by ZIMCHE, participants were of the view that the initial suspension created a negative perception towards ZOU's degree programmes. Statements such as - '. . . negative image of ZOU due to what was in the newspapers when ZIMCHE suspended some of our programmes' were repeatedly echoed by participants. The impact of attitude of students on enrolment was extensively documented by Basaza et al. (2013). In our view, the honours lie with the regional centre to correct this perception.

\subsubsection{Lack of e-learning facilities and a well-resourced library}

Literature on ODL identifies ICT facilities and well-resourced libraries as some of the key success factors which define the competitiveness of an ODL Regional Centre (Howell et al. 2003; Manal et al. 2007; Mafa et al. 2013). The challenge paused by these two key factors is aggravated by other related challenges such as inaccessibility of the regional centre and the poor road network to the regional centre from other parts of the province.

\subsubsection{Other challenges contributing to low student numbers}

Participants mentioned low pass rates in Mathematics and Science subjects, the tendency of potential students to migrate to Botswana and South Africa as well as the argument that some of the degree programmes offered at the regional centre were not market driven.

\subsection{Strategies employed by Matabeleland South ZOU Regional Centre to address the problem of low student numbers.}

Participants unanimously mentioned marketing as the major strategy that the regional centre was employing. The marketing strategies that were in use included - engagement of marketing agents; reproduction and distribution of all intake adverts to all the region's seven districts; exhibiting at provincial and district shows; participating in career days in various schools; and addressing stakeholders' meetings. However, what most participants said contradicted their earlier views on marketing - under challenges contributing to low student numbers the participants' general consensus was that there was no effective marketing in the region. We are tempted to go along with the earlier position. In our view, it will seem as if, instead of marketing being a concern of the whole regional staff, chances were that very few people were involved in the exercise. Additional strategies that were mentioned include employing customer care and attending to students' queries timeously. However, if figures in Table 1.1 are anything to go by, these endeavours at raising student numbers were not achieving the desired outcome. 


\subsection{Alternative Strategies to raise student numbers that were suggested by participants.}

Participants highlighted a number of alternative strategies that they viewed as prerequisites for increased student numbers. The frequently mentioned alternative strategies were:

- Having a marketing coordinator stationed at the regional centre in order to spearhead the marketing activities. This should be backed by adequate resources that are needed for marketing. Most participants concurred that this could result in aggressive marketing - where all the regional staff will be involved in marketing under the guidance of the marketing coordinator.

- Regional Programme Coordinators should be the drivers of the recruitment with different Faculties given targets per programme; and empowering and capacitating them to achieve these targets.

- An effective supervision and co-ordination system should be devised to maximise benefits from the use of marketing agents operating in designated zones.

- The regional centre should rope in influential alumni members as ambassadors in their spheres of influence.

- The regional centre should identify the major commercial activities in the district, and offer professional courses in those key activities.

- Civil servants should be made aware of the fee loan facility.

- The regional centre should open district centres.

- Participants suggested that the regional centre should be made more visible by inserting bill boards on all roads leading to the provincial capital. The bill boards should indicate where the regional centre is located.

- There was a suggestion that the library opening hours be extended in order to cater for employed students.

\section{Conclusions}

Basing on the above findings, it can be concluded that:

- The Matabeleland South ZOU Regional Centre is not readily accessible from the province's districts such as Matobo, Mangwe and Bulalima since people from most parts of these districts have to pass through Bulawayo to Gwanda. The proximity of the other two districts - Insiza and Umzingwane to Bulawayo is also a potential threat to Matabeleland South ZOU Regional Centre.

- Matabeleland South ZOU Regional Centre staff members have a positive perception of the key success factors that enhance competitiveness of an ODL regional centre.

- The absence of certain key success factors that enhance the competitiveness of an ODL regional centre could be contributing to low student numbers in Matabeleland South Regional Centre.

- Deploying in different geographical locations on its ownas suggested by participants may not be enough to raise enrolment numbers. The Regional Centre has to do something extraordinary to ensure that potential students from districts such as Matobo, Bulalima and Mangwe and some parts of Umzingwane and Insiza do not end up at ZOU Bulawayo Region. Examples of the services that district centre could offer include registration, distribution of registration packages, financial transactions, tutorials, library services, submission and collection of assignments, in the long run, writing of examinations and collection of results. Tutorials could also be delivered to the students via satellite.

\section{Recommendations}

Basing on the above conclusions, we recommend that:

- Matabeleland South Regional Centre should contextual the key success factors that are central to the competitiveness of an ODL centre.

- Some of the alternative strategies suggested by participants are plausible they need to be taken into consideration.

- The Regional Centre should seriously consider marketing its programmes in Botswana's Eastern District as well as the Limpopo Province of South Africa.

- In its marketing endeavours, the Regional Centre should make full use of facilities, opportunities, structures and stakeholders at its disposal.

- The regional centre should be assisted in developing core competences needed to contextualise key success factors.

- Finally, while it will be unethical to generalise findings from this case study to other regional centres of the university, ZOU's Senior Management may draw a number of useful lessons from this study. First, registration statistics in Table 1.1 illuminate that all regional centres are experiencing low student numbers. Second, chances are that challenges being experienced by Matabeleland South Regional Centre are generic to other regional centres. Third, limitations exhibited by Matabeleland South ZOU Regional Centre in contextualising key success factors that enhance the competitiveness of an ODL centre may also be obtaining in other regional centres. Therefore as ZOU's Senior Management Team contemplates how to 
reposition the ODL project in Zimbabwe, it may benefit from replicating this study at a national level, covering a number of regional centres.

\section{Journals}

\section{References}

[1]. Ali, A. \& Ahmad, I. (2011). Factors Determining Students' Satisfaction in Distance Learning Courses: A Study of AllamaIqbal Open University. Available at www.cedtech.net/articles/22/222.pdf.Accessed on 16/10/2013.

[2]. Angelino, L. M., Williams, F. K. \&Natvig, D. (2007).Strategies to Engage Online Students and Reduce Attrition Rates, The Journal of Education Online, 4(2), 1-14.Available at files.eric.ed.gov/fulltext/EJ907749.pdf.Accessed on 20/10/2013.

[3]. Arinto, P. B. (2013). A Framework for Developing Competencies in Open and Distance Learning, The International Review of Research in Open and Distance Learning, 14(1): 167-185.

[4]. Basaza, G. N., Milman, N. B., Wright, C. R. (2010). The Challenges of Implementing Distance Education in Uganda: A Case Study. The International Review of Research in Open and Distance Learning, 11(2).Available at www.irrodl.org/index.php/irrodl/article/view/833/154 Accessed on 20/11/2013.

[5]. Bonk, C. J. (2006). The Future of Online Teaching and Learning in Higher Education: The Survey Says . . Available at www.educause.edu/eor.article/future-online-teaching-and-learning-higher-education-survey-says. . . Accessed on 17/10.2013.

[6]. Howell, S. L., Williams, P. B. \& Lindsay, N. K. (2003). Thirty-two Trends Affecting Distance Education: An Informed Foundation for Strategic Planning. Online Journal of Distance Learning Administration, VI(111).Available at www.westga.edu/ distance/ojdla/fall63/howell63.html Accessed on 15/11/2013.

[7]. Mafa, O., Mpofu, J. \&Chimhenga, S. (2013). Combining Face-to-Face and Open and Distance Learning at the Zimbabwe Open University: Prospects, Challenges and Possibilities. Available at http://www.onlineresearchjournals.org/IJER Accessed on 24/12/13.

[8]. Manal, I., Kami, S.P.R. \& Ahmed, T. (2007). Institutional Factors Affecting Students' Intention to Withdraw From Distance Learning Programs in the Kingdom of Saudi Arabia: The Case of the Arab Open University (AOU). Available at www.westga.edu/distance/ojdla/spring101/ibrahim101.htm.Online Journal of Distance Learning Administration, Volume X, Number $1,2007$.

\section{Books}

[9]. Creswell, T. W. (2009). Research Design: Qualitative, Quantitative and Mixed Methods Approaches ( $3^{\text {rd }}$ edn.). London: SAGE.

[10]. Kumar, R. (2005). Research Methodology: A Step-By-Step Guide For Beginners ( $2^{\text {nd }}$ edn.). New Delhi: Pearson Education.

[11]. Kakhar, D. (2001). A framework for open distance learning - organization and management. Available at www.portlandpress.com/pp/books/onlie/vu/pdf/vu_ch3.pdf.Accessed on 16/10/2013.

\section{Proceedings papers}

[12]. SADC Secretariat (2009). Capacity Building in Open and Distance (ODL) Project: An Information, Education, and Communication Strategy for Open and Distance Aearning. Available at www.sadc.int/files/7213/7820/8535/IECStrategyFinalDraftForTranslation06.05.09.pdf Accessed 10/11/2013.

[13]. The Commonwealth of Learning. (2000). An Introduction to Open and Distance Learning. Available at www.col.org/SieCollectionDocuments/ODLIntro.pdf Accessed on 24/12/13.

[14]. The Commonwealth of Learning. (2004). Planning and Implementing Open and Distance Learning Systems: A Handbook for Decision Makers. Available at www.fao.org/sd/erp/toolkit/books/odlplanning.pdf

[15]. Tresman, S. (2002). Towards a Strategy for Improved Student Retention in Programmes of Open, Distance Education: A Case StudyFrom the Open University UK, In The International Review in Open and Distance Learning.Available at www.irrodl.org/index.php/irrodl/article/viewArticle/75/145.Accessed on 18/10/2013.

[16]. UNESCO (2002). Open and Distance Learning: Trends, Policy and Strategy Considerations. Available at http://unesco.org/images/0012/00128/128463e.pdf Accessed on 10/11/2013.

[17]. UNESCO Institute for Information Technologies in Education (IITE). (2000).Distance Education for the Information Society: policies, pedagogy and professional development. Available athttp://www.iite.ruAccessed on 16/10/2013. 